Published in final edited form as:

Ann Thorac Surg. 2013 October ; 96(4): . doi:10.1016/j.athoracsur.2013.06.084.

\title{
Who Should Adopt Robotic Surgery, and When?
}

\author{
Jessica K. Smyth, MD ${ }^{1}$, Karen E. Deveney, MD, FACS ${ }^{2}$, and Robert M. Sade, MD ${ }^{3}$ \\ ${ }^{1}$ Department of Otolaryngology, University of North Carolina, Chapel Hill, NC \\ ${ }^{2}$ Department of Surgery, Oregon Health and Science University, Portland, OR \\ ${ }^{3}$ Department of Surgery, Division of Cardiothoracic Surgery, and Institute of Human Values in \\ Health Care, Medical University of South Carolina, Charleston, SC
}

\section{Keywords}

Ethics; professional affairs; robotic surgery

New technologies abound in the surgical specialties, cardiothoracic surgery in particular. One of the more highly visible and controversial new technologies is robotic surgery some claim that it is a useful adjunct to surgery, others that it is mostly a marketing tool. Assuming that it has a high utility value, however, when should it be adopted in practice, and by whom? The following case serves to focus discussion of opposing points of view.

\section{The Case}

Dr. Pierre Jaloux, a 55-year-old highly respected cardiothoracic surgeon, hires Dr. Woody Randolph, a young well-trained surgeon who has recently finished fellowship training in robotic surgery. The older surgeon plans to cut back on his practice in about 10 years to work part time. Six months later, Dr. Randolph has developed a busy practice in robotic surgery and has a growing reputation for very good outcomes. Dr. Jaloux finds his patient load declining because referring physicians and patients are impressed by the robotic procedures. He has feelings of competitiveness and even jealousy toward his new colleague, although they remain friendly and Dr. Randolph is, by any measure, clearly doing a great job. The older surgeon decides to take a two-week course in robotic surgery and use the technology in his own practice to better compete with his young colleague. Should Dr. Jaloux carry out his plan?

Pro

Jessica K. Smyth, MD

Presented with the case of Dr. Jaloux, you may ask yourself, "How can any surgeon justify performing an operation when there is another surgeon available who is more experienced or skilled?" The mistake in this line of thinking is twofold. The first error is equating technical skill or experience with competence. Based solely on technical skill, one may falsely

(C) 2013 The Society of Thoracic Surgeons. Published by Elsevier Inc. All rights reserved.

Address for correspondence: Robert M. Sade, M.D. Medical University of South Carolina 25 Courtenay Drive Suite 7028, MSC 295 Charleston, SC 29425-2270 sader@ musc.edu; www.values.musc.edu 8437925278 (office); 8437923858 (fax); 8433450480 (cell).

Publisher's Disclaimer: This is a PDF file of an unedited manuscript that has been accepted for publication. As a service to our customers we are providing this early version of the manuscript. The manuscript will undergo copyediting, typesetting, and review of the resulting proof before it is published in its final citable form. Please note that during the production process errors may be discovered which could affect the content, and all legal disclaimers that apply to the journal pertain. 
conclude that the best technician is the best surgeon. However, competence includes more than technical proficiency. Competence is the exercise of the required knowledge, judgment, and skill to perform a particular task reliably in order to produce an appropriate outcome.

The second flaw in this line of thinking is equating competence with perfection. At each institution in this country, it is likely there are a great number of competent surgeons. Sound quality assurance in surgery should provide patients with surgical care that is above the morally required threshold of competence similar to the safety standards for aircraft pilots and bridge builders. Fine grained distinctions of proficiency and expertise may be helpful in identifying appropriate surgeons for unusually complex cases, but it's unnecessary, and may be counterproductive, to make expertise rather than competence the reference standard for all surgical care.

As a highly respected academic surgeon, Dr. Jaloux has likely demonstrated a high degree of competence, not only in his own performance, but also in his ability to oversee and train others. We can assume that over the course of his career, he has integrated new evidence and technology into his practice. Surgeons of all specialties are integrating evidence based medicine and new technologies they mastered after residency training into their current practices. For example, neurosurgeons and otolaryngologists are now using an endoscopic transnasal trans-sphenoidal approach for the resection of many pituitary adenomas.[1] In orthopedic surgery, treatment of femoral shaft fractures has evolved from traction and casting to locked intramedullary nailing. [2] Cardiothoracic surgeons are rapidly adopting the recently approved technology of transcatheter aortic valve replacement for use when open replacement is deemed high risk.[3] Leading practitioners must incorporate new techniques after their formal training is complete to employ current best practices.

And isn't this one of the greatest draws of medicine...to be challenged, to continually learn and refine our expertise?

The daily responsibility for successfully performing invasive procedures on another human being distinguishes surgery from other branches of medicine. This is a sobering reminder. What allows an individual surgeon to do this? Our ability to operate comes not only from knowledge and technical expertise, but also through connecting with patients in such a way that they have confidence in our capabilities.

Over the course of his career, the Dr. Jaloux has assuredly developed significant relationships with his patients and their families. This supportive environment adds to the overall care he provides to them. Given that the number of patients has decreased, it is clear that his current scope of practice is not meeting their expectations. How many times has one of your patients said to you, "Well, I read on the internet that this technique was better than that technique or that this course of treatment was better for my illness." Gaining this skill set will enable the senior physician to not only offer robotic surgery, but also be able to discuss the advantages and disadvantages and counsel his patient on the best treatment choice for their particular situation.

Ultimately the decision to pursue further training in order to effectively incorporate advanced technology into his practice should not stem from personal interests, but from what is in the best interest of the patients he serves. The scenario suggests that he is motivated by feelings of jealousy and competitiveness; however, the question to ask yourself it this...how many can boast only altruistic motivation for every choice along their career path? Oftentimes, decisions or actions are based on personal motives. However, further training and education most commonly result in better performance and better outcomes for the patient. The patient and the public may be harmed if physicians make clinical decisions 
based on factors other that what is best for the patient. That being said, having the capability to offer his patients multiple treatment options may be in the best interest of the patient.

So the crux of the scenario remains...how can a surgeon safely incorporate evolving technology into his practice?

Across the globe, healthcare delivery is undergoing a major evolution. The introduction of new technologies, the use of telemedicine to deliver health care remotely, and the evolving restrictions in work hours of trainee physicians are changing the face of medicine. Training physicians and surgeons in more specialized techniques, in shorter periods of time, while maintaining the highest levels of patient safety and in a cost-effective manner is a challenging order. This introduction of new technology and evolution of education and health care delivery should lead to improvement without harming patients in the process.

Robotic surgery was developed in response to the limitations and drawbacks of laparoscopic surgery. Since 1997 when the first robotic procedure was performed, various papers have been published highlighting the advantages of this technique. The robotic system offers several features, including intuitive movements, tremor filtration, stereoscopic vision, and motion scaling, which are thought to contribute to making robotic-assisted surgery more intuitive to conceptualize and master.[4]

In a study performed by Kaul and colleagues, operative times and learning curves were drawn for three surgeons: an experienced laparoscopic surgeon who had performed more than 1000 procedures; an experienced open surgeon who was performing his or her first robotic radical prostatectomy, and a fellow who started performing robotic radical prostatectomies after having assisted and observed during more than 100 robotic procedures.

The robot decreased the learning curve for the experienced open surgeon such that by case 7 , the operative times using the robot were faster than those of the experienced laparoscopic surgeon, who had performed more than 1000 laparoscopic procedures. The fellow, who was mentored in robotics, performed his first robotic case faster than surgeons A and B, both of whom were more experienced surgeons.[4]

Although our scenario implies that Dr. Jaloux intends to go to a two-week course and then introduce the technology into his own practice, there are professional standards and likely institutional requirements before he would be able to incorporate this technology in the operating room. He could begin with the course and then be mentored at his home institution by other surgeons already trained in robotics before he would be allowed to practice independently. Additionally, some institutions are now purchasing robotic simulators to aid staff in acquiring robotic skills.

Finally, this discussion wouldn't be complete without touching on the subject of age. What weight should be placed on the fact that the senior surgeon is 55? It is not uncommon for professionals to work well into their 60s and 70s. As a gauge, the average age of an incoming president is 55. Age is not, in and of itself, impairing. Studies on learning and age demonstrate that motivation and positive self-perception are directly linked to our capability to learn.

But let us be guided by words of the English physician, Dr. Thomas Percival, "Let both the Physician and Surgeon never forget that their professions are public trusts, properly rendered lucrative whilst they fulfill them, but which they are bound by honor and probity to relinquish as soon as they find themselves unequal to their adequate and faithful execution." [5] 
As I conclude, let me summarize - surgical care involves lifelong learning which should be directed on improving patient outcomes and may continue as long as there is due diligence to our professional obligations.

\section{Con}

\section{Karen E. Deveney, MD, FACS}

No, it would be wrong for Dr. Jaloux to take a two-week course in robotic surgery to compete with his younger, fellowship-trained colleague.

I base my opinion on three diverse arguments: 1) the effects of age on cognitive function, dexterity, and ability to learn new technologies; 2) the inappropriate, unethical reasons that are motivating him to learn robotics; and 3) the increased cost and lack of demonstrated superiority of robotic procedures.

Studies on cognitive function have demonstrated unequivocally that measured IQ declines in adults as they age. The average IQ of 100 in the 25-34 year old decreases to 90 by age 55-64, 82 by age 65-74, and 73 for those over age 75.[6] Although these data apply to a general population and not M.D.'s, studies that compare the abilities of non-M.D.'s and M.D.'s of varying ages performing tests measuring physical and mental traits such as reactivity, attention, numeric recall, verbal memory, visiospatial facility, reasoning, and mental calculation show that M.D.'s decline with age more slowly, but still show a decrease of $5 \%$ in their total scores by age 60 and $10 \%$ by age 70.[7]

A study that looked specifically at cognitive and physical function of surgeons as they age was conducted using surgeon volunteers 45 years and older who were attending the Clinical Congress of the American College of Surgeons (ACS) between 2001 and 2006. Surgeons took a battery of tests measuring attention, reaction times, visual learning, and memory. The studies showed a gradual decline in all areas with aging.[8]

Studies of general surgeons recertifying on the American Board of Surgery examination show that the failure rate on the examination dramatically increases with age, from a mean of $3.6 \%$ on the first recertification taken 10 years after initial Board certification to $10.3 \%$ at 20 years and $16.9 \%$ at 30 years. [9]

Although the above studies show that age is associated with a decline in cognition and knowledge and skill on surrogate tests of physical functioning, some would argue that the increased surgical experience with age can compensate for the decreased mental agility and manual dexterity that accompany aging. In fact, the effects of age and experience were studied as factors in outcomes of inguinal hernia repair in the much-quoted randomized, controlled, multi-institutional VA cooperative study of laparoscopic versus open inguinal hernia repair. In that study surgeons older than age 45 who had performed fewer than 250 laparoscopic repairs had a mean hernia recurrence rate of $18 \%$ compared to $3.4 \%$ for surgeons younger than age 45.[10] This finding is consistent with results of a systematic review by Choudhry et al in which all but one of 59 studies found some decline in performance with increasing age or time in practice.[11] Are these poorer outcomes fair to patients?

Opportunities for fully-trained, older surgeons to learn new procedures are often limited to short courses with their inherent limitations on opportunities to practice a procedure longitudinally as is seen over the course of a several-year residency or even a two-year fellowship. To perform robotic procedures requires not only a course, but also practice time on a trainer and proctoring in active practice. The steep learning curve of robotic 
cardiothoracic surgery has been explored in a few small studies in the literature. In one study of robotic CABG, 4 of 5 adverse graft outcomes occurred in the first quintile of cases. These authors reviewed the reported experience at other centers and concluded that "even in the most experienced hands limited-access, telerobotic CABG involves a significant learning curve."[12] The steep learning curve has been looked at for complex robotic operations in other surgical specialties such as urology. After initial robotic training performing prostatectomy, it was found that 110-200 cases were necessary for a surgeon experienced in open procedures to achieve the level of competence that would demonstrate mastery of the robotic procedure.[13] The long learning curve for complex robotic procedures certainly takes it beyond a two-week course, especially in an older surgeon with diminishing cognitive and physical skills.

Privileging to perform robotic procedures requires not only a formal course, but also a period of proctoring in practice. Who would be willing to provide such proctoring? The older surgeon's younger partner would be the natural person to proctor him, but for him to do so would detract from his own practice and also set up an awkward dynamic in which the younger surgeon may feel obligated to approve of the older surgeon's technical skills prematurely since they are partners. Finding a surgeon from elsewhere to proctor him for an adequate time would be difficult.

Finally, it may be anecdotal, but a prominent and famous academic endocrine surgeon, Atul Gawande, recently confessed that his outcomes had plateaued and he was no longer "beating the averages." He wondered "Maybe this is what happens when you turn forty-five." $\mathrm{He}$ went on to say, "Surgery is, at least, a relatively late-peaking career"...not like math, baseball, or pop music (peak at 30), but more like S \& P 500 CEO's (average age of hire=52) or age of maximum productivity for geologists, 54. "Surgeons apparently fall somewhere between the extremes, requiring both physical stamina and the judgment that comes with experience. Apparently, I'd arrived at that middle point."[14]

The second argument against the older surgeon's learning robotic surgery to compete with his younger partner is that his motivation is self-serving. Self-interest should never be an ethical justification for any action in the practice of medicine. One need look no further than the motto of the American College of Surgeons (ACS): "Omnibus per artem fidemque prodesse" (To serve all with skill and fidelity). Furthermore, the ACS mission statement maintains that "The American College of Surgeons is dedicated to improving the care of the surgical patient and to safeguarding standards of care in an optimal and ethical practice environment." [15] The basic principles of medical ethics require that one place the interests of the patient above those of their own interest such as personal gain, promotion, or fame. [16]

The third and last issue in this case is to query whether robotic surgery has even been shown to improve the care of the surgical patient. To date there is no evidence to support the superiority of robotic surgery over open surgery for any procedure. Although potential advantages of robotic procedures include better " 3 -D" vision, better magnification, decreased hand tremor, and facilitated suturing in a small space, robotic procedures also take longer, cost more, and are at best equivalent to open procedures in outcomes.[17] The role of robots in cardiac surgery has not been fully defined and, though it has "immense longterm potential to minimize morbidity and improve the outcomes of CABG procedures," only "highly specialized centers" can afford the cost and garner adequate experience to justify its use. [13] In one study the author surveyed all U.S. institutions that owned a da Vinci robot concerning the yearly volume of robotic heart operations and found that only an average of 7.3 cardiac operations were performed annually per robot, representing only $0.5 \%$ of all cardiac operations. Only $12 \%$ of programs performed more than 50 robotic procedures 
yearly. Although some centers did report good outcomes with robotic cardiac procedures, the outcomes did not exceed those of comparable minimally-invasive methods.[18]

For all of the above reasons, then, it would be wrong for the older surgeon to attend a twoweek robotic surgery course with the goal of competing with his younger, fellowship-trained colleague.

\section{Concluding Remarks}

Robert M. Sade, M.D.

Smyth and Deveney address three broad ethically relevant areas: mental and physical functioning, motivation, and effectiveness of robotic surgery. I would add a fourth to those three: marketing.

\section{Mental and Physical Function Related to Age}

The debaters agree that two weeks of robotic training is inadequate to develop clinical competence; additional training on a simulator and a period of proctoring will be necessary. Deveney points to declining cognitive and physical functioning with age, though less so in physicians than others. Smyth does not challenge those findings, but emphasizes the importance of non-cognitive traits, such as experience, judgment, and adaptability, in determining competence. Both essayists analyze the question in general terms, but neither mentions the importance of individual variation. What should Dr. Jaloux, specifically, do? Much depends on his individual characteristics; for example, a highly intelligent and dexterous surgeon can lose $5 \%$ or $10 \%$ of his IQ and dexterity and still be highly intelligent and dexterous. On this point, I believe Smyth makes the stronger case.

\section{Motivation}

Deveney finds Dr. Jaloux's motivation to be self-serving and asserts, "Self-interest should never be an ethical justification for any action in the practice of medicine." "Never" is a strong word, and it seems likely that we can never entirely rid ourselves of self-interest. One wonders whether attempting to maintain one's practice volume and the income it generates crosses an ethical line into unacceptable territory. Arguing to the contrary, Smyth suggests that jealousy and competitiveness may not be such a bad thing because for surgeons, "Oftentimes, decisions or actions are based on personal motives." She softens this statement by pointing out that adopting new technologies commonly improves patient outcomes, but we can wonder whether it is right to base decisions on personal motives. Underlying motives are notoriously difficult to analyze and are seldom uncomplicated. Dr. Jaloux's motivation probably is not simple, and includes concern for the safety and benefit of his patients. Most decisions surrounding patient care have complex motivations; ethically, the greatest weight must be given to the interests of the patient.[19] I believe Deveney has made the better case on this point.

\section{Effectiveness of Robotic Surgery}

Ethical decision making in clinical medicine often requires weighing of benefits and harms first to the patient, then balancing benefits and harms to others, such as the physician, his partners, the hospital, and society in general. Dr. Jaloux faced this balancing act in deciding whether to learn robotic surgery. A critical factor is the potential for harm to his patients. For reasons Smyth enumerates, it seems likely that Dr. Jaloux can become competent at robotic lobectomy, and if he does not, the training and proctoring processes should inform him and others that he should not use this technique clinically. 
Are the outcomes after robotic lobectomy better than, similar to, or worse than those after more standard approaches? Early reports suggest that initial survival and other outcome measures may be similar to standard approaches, [20,21] but followup reports have been sparse[22] and comparisons of lobectomy techniques could be the topic of another debate, which is beyond the scope of the present one. For our purposes, there seems to be no decisive clinical advantage or disadvantage to robotic lobectomy compared with open and VATS approaches.

\section{Marketing}

Much of the growth in robotic surgery may be driven by marketing efforts of hospitals and surgery programs.[23] Is there something intrinsically wrong with using new technologies to preserve or increase the patient base of a hospital or practice?

At one time, marketing was considered to be unethical, typified by this statement in the Principles of the American Medical Association (AMA) Code of Medical Ethics of 1957, Section 5: "A physician ... should not solicit patients."[24] This was taken to mean that all forms of advertising other than a simple public statement of name, address, telephone number, and nature of practice were unethical. A lawsuit alleging restraint of trade against the AMA by the Federal Trade Commission in 1975 resulted in an agreement in 1988 that included the AMA's removal of the prohibition against solicitation of patients from the Code of Medical Ethics.[25] For the last 25 years, advertising and other forms of marketing that are not false, deceptive, or misleading are deemed to be legal and are increasingly felt to be ethically acceptable. For many, however, some forms of legal marketing, such as using new technologies to build surgical volume, fail the sniff test. Yet, as long as new technologies are used competently, full and accurate information about advantages and disadvantages is provided, and patients are not harmed, there seems to be nothing intrinsically wrong with marketing.

Surgeons using robotic technology could be flirting with ethical boundaries, however, if they become involved with certain kinds of promotional activities; such issues are beyond the scope of the present case.

\section{Conclusion}

Dr. Jaloux has already made his decision to seek training in robotic surgery. The essayists both gave persuasive reasons why he should or should not decide to seek robotic training. They were not asked to advise him on what decision he should make, however; rather, they were asked to determine whether he should carry out the plan he has already made. We should assume that this highly respected surgeon's decision was based on adequate selfassessment of his own strengths and limitations, and that he knows the only partially understood advantages and disadvantages of robotic lobectomy. Without good reason to believe his patients will be harmed, we seem not to have sufficient evidence to tell Dr. Jaloux that the decision he has made was wrong.

\section{Acknowledgments}

Disclosures

Dr. Sade's role in this publication was supported by the South Carolina Clinical \& Translational Research Institute, Medical University of South Carolina's Clinical and Translational Science Award Number UL1RR029882. The contents are solely the responsibility of the authors and do not necessarily represent the official views of the National Center For Research Resources or the National Institutes of Health. 


\section{References}

1. Loyo-Varela M, Herrada-Pineda T, Revilla-Pacheco F, et al. Pituitary Tumor Surgery: A Review of 3004 Patients. World Neurosurg. 2012 PubMed. Epub ahead of print.

2. Blasier RB. The Problem of the Aging Surgeon: When Surgeon Age becomes a Surgical Risk Factor. Clin Orthop Relat Res. 2009; 467:402-411. [PubMed: 18975041]

3. Stone ML, Kern JA, Sade RM. Transcatheter aortic valve replacement: clinical aspects and ethical considerations. Ann Thorac Surg. In Press.

4. Kaul S, Shah NL, Menon M. Learning Curve Using Robotic Surgery. Curr Urol Rep. 2006; 7:125129. [PubMed: 16526997]

5. Percival, T. Medical ethics, or, A code of institutes and precepts, adapted to the professional conduct of physicians and surgeons. Johnson \& Bickerstaff; London: 1803.

6. Kaufman, AS. Assessing adolescent and adult intelligence. Allyn and Bacon; Boston: 1990.

7. Powell, D. Profiles in cognitive aging. Harvard University Press; Cambridge, MA: 1994.

8. Bieliauskas LA, Langenacker S, Graver C, et al. Cognitive changes and retirement among senior surgeons: Results from the CCRASS study. J Am Coll Surg. 2008; 207:69-79. [PubMed: 18589364]

9. Rhodes RS, Biester TW. Certification and maintenance of certification in surgery. Surg Clin N Am. 2007; 87:825-836. [PubMed: 17888782]

10. Neumayer LA, Gawande AA, Wang J, et al. Proficiency of surgeons in inguinal hernia repair: Effect of experience and age. Ann Surg. 2005; 242:344-352. [PubMed: 16135920]

11. Choudhry NK, Fletcher RH, Soumerai SB. Systematic review: The relationship between clinical experience and quality of health care. Ann Intern Med. 2005; 142:260-273. [PubMed: 15710959]

12. Novick RJ, Fox SA, Klail BB, et al. Analysis of the learning curve in telerobotic, beating heart coronary artery bypass grafting: a 90 patient experience. Ann Thoracic Surg. 2003; 76:749-753.

13. Doumerc N, Yuen C, Saudie R, et al. Should experienced open prostatic surgeons convert to robotic surgery? The real learning curve for one surgeon over three years. BJU International. 2010; 106:378-384. [PubMed: 20067454]

14. Gawande, AA. Personal Best. The New Yorker; Oct 3. 2011

15. [November, 2012] American College of Surgeons Bulletin and website, www.facs.org

16. McGrath, MH.; Risucci, DA.; Schwab, A. Ethical issues in clinical surgery. American College of Surgeons; Chicago: 2007.

17. Rawlings AL, Woodland JH, Vegunta K, et al. Robotic versus laparoscopic colectomy. Surg Endosc. 2007; 21:1701-1708. [PubMed: 17353988]

18. Robicsek F. Robotic cardiac surgery: Time told! J Thorac Cardiovasc Surg. 2008; 135:243-246. [PubMed: 18242242] Council on Ethical and Judicial Affairs. Code of Medical Ethics of the American Medical Association, 2012-2013 Ed. American Medical Association; Chicago: 2012. Principle VIII.; p. lxxi-lxxv.

19. Jang HJ, Lee HS, Park SY, Zo JI. Comparison of the early robot-assisted lobectomy experience to video-assisted thoracic surgery lobectomy for lung cancer: a single-institution case series matching study. Innovations (Phila). Sep; 2011 6(5):305-10. [PubMed: 22436706]

20. Yu HY, Friedlander DF, Patel S, Hu JC. The current status of robotic oncologic surgery. CA Cancer J Clin. Jan; 2013 63(1):45-56. [PubMed: 23161385]

21. Park BJ, Melfi F, Mussi A, et al. Robotic lobectomy for non-small cell lung cancer (NSCLC): long-term oncologic results. J Thorac Cardiovasc Surg. Feb; 2012 143(2):383-9. [PubMed: 22104677]

22. Schiavone MB, Kuo EC, Naumann RW, et al. The commercialization of robotic surgery: unsubstantiated marketing of gynecologic surgery by hospitals. Am J Obstet Gynecol. Sep.2012 207(3): 174. [PubMed: 22835493]

23. Judicial Council, American Medical Association. [February 13, 2013] Principles of Medical Ethics. Available at http://www.ama-assn.org/resources/doc/ethics/1957_principles.pdf.

24. Hirsh BD. Antitrust and Medical Ethics. JAMA. 1983; 250(20):2759-60. [PubMed: 6644949] 